\title{
Navigating the complex path between the oxytocin receptor gene (OXTR) and cooperation: an endophenotype approach
}

\author{
Brian W. Haas ${ }^{1,2}$, Ian W. Anderson ${ }^{1}$ and Jessica M. Smith ${ }^{2}$ \\ 1 Department of Psychology, University of Georgia, Athens, GA, USA \\ 2 Interdisciplinary Neuroscience Graduate Program, University of Georgia, Athens, GA, USA
}

\section{Edited by:}

Susanne Leiberg, University of Zurich, Switzerland

\section{Reviewed by:}

Maria Barth, Tufts University, USA

Hidenori Yamasue, University of

Tokyo, Japan

${ }^{*}$ Correspondence:

Brian W. Haas, Department of

Psychology, University of Georgia,

125 Baldwin Street, Athens,

30602 GA, USA

e-mail: bhaas@uga.edu

\begin{abstract}
Although cooperation represents a core facet of human social behavior there exists considerable variability across people in terms of the tendency to cooperate. One factor that may contribute to individual differences in cooperation is a key gene within the oxytocin (OT) system, the OT reception gene (OXTR). In this article, we aim to bridge the gap between the OXTR gene and cooperation by using an endophenotype approach. We present evidence that the association between the OXTR gene and cooperation may in part be due to how the OXTR gene affects brain systems involved in emotion recognition, empathy/theory of mind, social communication and social reward seeking. There is evidence that the OXTR gene is associated with the functional anatomy of the amygdala, visual cortex (VC), anterior cingulate and superior temporal gyrus (STG). However, it is currently unknown how the OXTR gene may be linked to the functional anatomy of other relevant brain regions that include the fusiform gyrus (FG), superior temporal sulcus (STS), ventromedial prefrontal cortex (VMPFC), temporoparietal junction (TPJ) and nucleus accumbens (NAcc). We conclude by highlighting potential future research directions that may elucidate the path between OXTR and complex behaviors such as cooperation.
\end{abstract}

Keywords: OXTR, genetics, oxytocin, social-cognition, cooperation

\section{INTRODUCTION}

Human beings have a unique affinity towards cooperating with one another to accomplish goals. The act of cooperation involves a common effort within a group for the collective benefit rather than seeking to accomplish goals solely for oneself. Cooperative people are characterized as socially tolerant, empathic, helpful, and compassionate (Cloninger et al., 1993). Although the tendency to cooperate is a common attribute across many people and cultures, there also exists considerable variability between people in cooperative motivation and behavior (Wischniewski et al., 2009). In this article, we highlight recent progress towards identifying genetic factors that contribute to individual differences in cooperation. Within this framework, we focus our attention on the oxytocin (OT) system and brain regions that subserve the tendency to cooperate.

Cooperation has been empirically investigated in several different ways. One common way that cooperation has been studied within social psychology and economic research is to use the Prisoner's Dilemma task. The prisoner's dilemma task provides the opportunity to characterize the value one attributes to their own outcome versus the value one attributes to the outcome of the entire group. Results of this research demonstrate that humans often act more cooperatively than a strict self-interest strategy would predict (Komorita and Parks, 1999).

Although many humans tend to be driven towards cooperation, there also exists considerable variability among people in how cooperative they tend to be (Wischniewski et al., 2009). For example, individual differences in personality traits, such as with agreeableness and conscientiousness, are associated with the tendency to cooperate (Witt et al., 2002; Volk et al., 2011). Another factor that may influence cooperation across humans is genetics (Cesarini et al., 2008). Many of the genes implicated in cooperation are known to affect the function of hormonal and neurotransmitter systems within a network of brain regions important for social-cognition.

One hormone associated with individual differences in cooperation and with the function of brain regions involved in socialcognition is OT (Ebstein et al., 2012; Yamasue, 2013). OT is a neuropeptide primarily synthesized in the hypothalamus and has broad effects on OT receptors throughout the central nervous system (Gimpl and Fahrenholz, 2001). One way to investigate the effect of OT on social behavior is to manipulate OT levels via intranasal administration. Following OT administration people display greater amounts of cooperative behavior as compared to individuals receiving placebo (Kosfeld et al., 2005; Declerck et al., 2013). These findings have motivated the search for genes within the OT system that are linked to individual differences in cooperation.

One gene within the OT system that has been linked to prosocial behaviors, such as cooperation, is the OT receptor gene (OXTR). OXTR is a gene located on chromosome 3p25 that codes for OT receptors (Kimura et al., 1992). There are 
several single nucleotide polymorphisms (SNPs) of OXTR, each of which codes for particular attributes of the OT receptor. Studying how behavioral or biological metrics vary according to OXTR SNPs provides insight as to the function of the OXTR gene. In this article, we focus on findings comparing social cognitive metrics, as related to cooperation, based on OXTR SNPs.

Behavioral genetic studies associating polymorphisms of the OXTR gene with laboratory measures of cooperation have revealed a mixed group of results. Israel et al. (2009) and Tabak et al. (2013) demonstrated an association between OXTR and lab measures of cooperation including the Dictator Game and the Social Values Orientation and Prisoner's Dilemma tasks. On the other hand, Apicella et al. (2010) reported no association between OXTR and cooperation during the Dictator and Trust Game. The inconsistency across these studies may indicate that OXTR is associated with some, but not all, of the underlying components of cooperative behavior in humans.

One effective method used to investigate the association between genes and complex behaviors, such as cooperation, is to use an endophenotype approach. An endophenotype represents an intermediate level between gene expression and a complex behavior or disease state (Gottesman and Gould, 2003). For example, there may be a weak or moderate association between a gene and the onset of an anxiety or mood disorder based on how the gene codes for the organization of neurons that react to psychosocial stress. In this example, the neuronal response to psychosocial stress is considered an endophenotype that exists between the gene and disease (Hamer, 2002; Gottesman and Gould, 2003). Considering endophenotypes holds promise in terms of elucidating the genetic etiology of cognition, social behavior and psychopathology.

\section{A COMPONENT VIEW OF COOPERATION AND THE COOPERATIVE BRAIN}

The ability to cooperate effectively with others relies on a set of underlying social-cognitive constructs (Brosnan et al., 2010). Successful cooperation requires social cognitive constructs that include (but not limited to) to (i) acknowledging and recognizing the emotional states of others within a group (emotion recognition) (Elfenbein et al., 2007; Krumhuber et al., 2007); (ii) accurately interpreting the intentions of others (empathy/theory of mind) (Sally and Hill, 2006; Paal and Bereczkei, 2007); (iii) communicating effectively with others (social communication) (Miller et al., 2002); and (iv) seeking out and valuing social interaction (social reward seeking). Thus, effective cooperation may be characterized by the availability of specific socialcognitive resources. Considering each of these social cognitive constructs independently may elucidate how genes within the OT system influence cooperative motivation and behavior in humans.

Neuroimaging research demonstrates that specific brain networks carry out many of the social-cognitive constructs underlying cooperation. The ability to accurately acknowledge and recognize the emotional states of others (emotion recognition) is carried out through the ventral processing stream and relies on visual cortices, the fusiform gyrus (FG), superior temporal sulcus (STS) and areas within the prefrontal cortex (Figure 1A). The visual centers of the brain are within an emotional attention circuit (Rudrauf et al., 2008). When faced with information of high emotional saliency, the amygdala and visual cortex (VC) function to increase local attention recourses (Morris et al., 1998). The FG contains the fusiform face area, which is a highly specialized region for distinguishing between different types of faces (Kanwisher et al., 1997). The amygdala functions to signal and tag information that is highly emotionally salient (Aggleton, 2000). The STS is involved in processing social and emotional signals conveyed via body or biological motions (Thompson and Parasuraman, 2012). Lastly, the ventromedial and dorsolateral prefrontal cortex (DLPFC) categorizes and evaluates the salience of emotional stimuli (Mitchell and Greening, 2012; Roy et al., 2012). Combined, this brain network subserves the ability to evaluate and categorize the emotional states of others.

Being able to accurately interpret the intentions of others (empathy and theory of mind) relies on a brain network that includes areas within the frontal, temporal and parietal cortices (Figure 1B). The dorsomedial prefrontal cortex (DMPFC) and dorsal anterior cingulate cortex (ACC) generate appropriate emotional responses to other people's mental states (i.e., emotional empathy) (Fan et al., 2010). While the temporoparietal junction (TPJ) is involved in accurately interpreting the mental states and intentions of others (i.e., cognitive empathy or theory of mind) (Decety and Lamm, 2007). Together, these brain structures subserve the ability to accurately understand and respond to the emotions and intentions of other people.

Social communication (the ability to perceive, transmit and understand information between people) relies on brain regions that include several areas within the temporal and frontal lobes (Figure 1C). The superior temporal gyrus (STG) processes verbal and non-verbal social cues (Hickok and Poeppel, 2007; Hein and Knight, 2008). The superior temporal gyrus contains the primary auditory cortex, which functions to decode vocal communication signals (Hickok and Poeppel, 2007). Lastly the inferior frontal gyrus (IFG), and the premotor cortex (PMC) are both important regions involved in speech production (Price, 2012). Together, the integrity of these brain structures is critical for effective social communication to occur.

Being driven towards social interaction and the subjective sense of reward in response to social interaction may be associated with the tendency to cooperate. The subjective motivation towards social interaction is subserved by a brain network involved in salience and reward processing and includes the dopaminergic system and several regions within the ventral striatum and frontal lobe (Haber and Knutson, 2009; Figure 1D). Within the striatum, the nucleus accumbens (NAcc) is a critical area involved in reward processing and is conceptualized as the brain's "pleasure center." Within the frontal lobe, the ventromedial prefrontal cortex (VMPFC) and ACC function to signal and anticipate potential rewards (Rushworth et al., 2011). Thus, the brain's reward circuitry may contribute to how social interactions are experienced and valued during conditions that involve cooperation. 


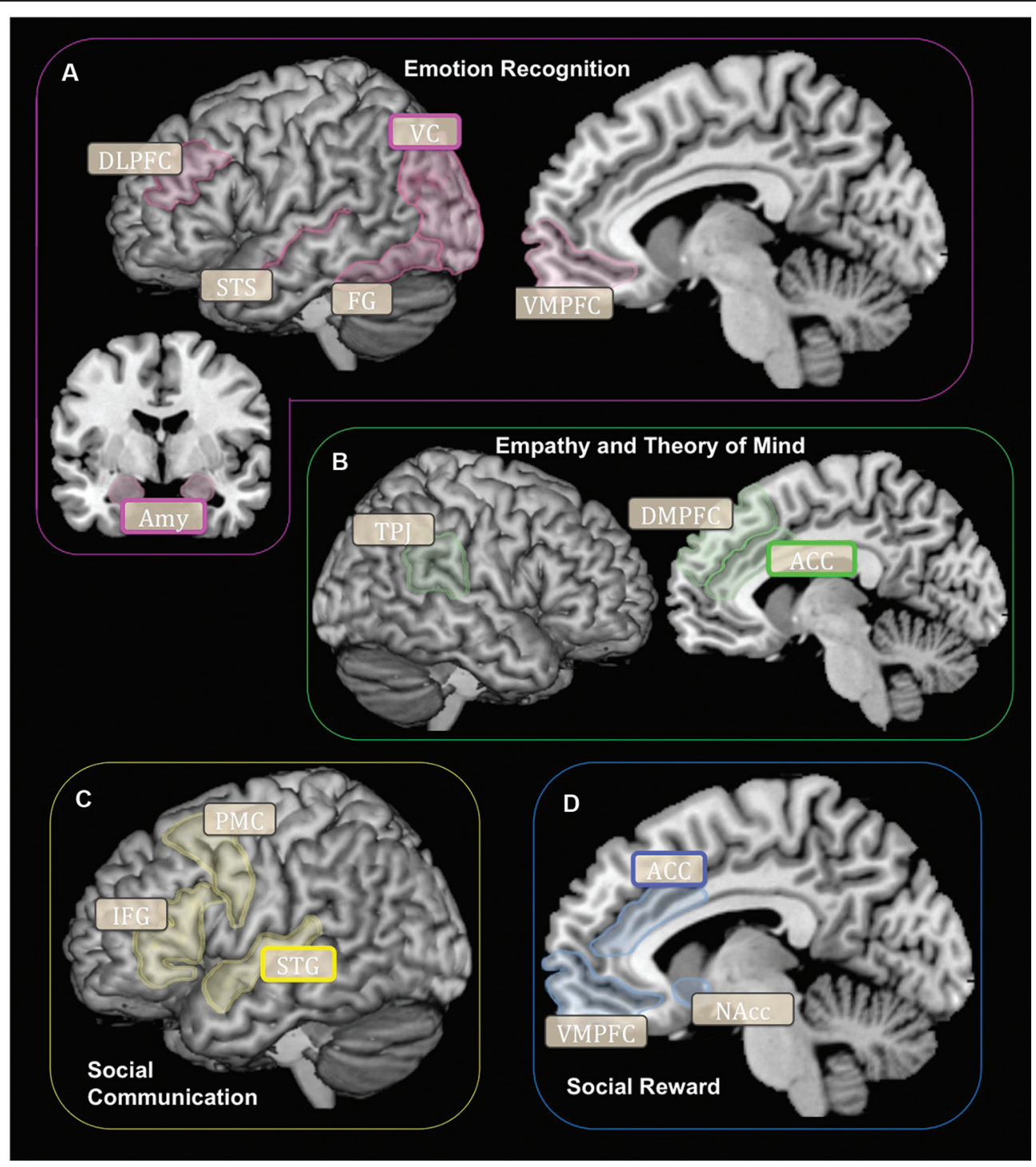

FIGURE 1 | Schematic representation of brain networks subserving cooperation for each social-cognitive component: (A) Emotion Recognition, (B) Empathy and Theory of Mind, (C) Social Communication, (D) Social Reward. Rounded boxes (with bold or grey outlines) signify brain regions implicated in social-cognitive constructs subserving cooperation. Rounded boxes with bold outlines signify brain regions shown to be structurally or functionally different according to the OXTR gene (SNPs or methylation) in humans. DLPFC, Dorsolateral Prefrontal Cortex; VC, Visual Cortex; STS, Superior Temporal Sulcus; FG, Fusiform Gyrus; VMPFC, Ventromedial Prefrontal Cortex; Amy, Amygdala; TPJ, Temporoparietal Junction; ACC, Anterior Cingulate Cortex; PMC, Premotor Cortex; IFG, Inferior Frontal Gyrus; STG, Superior Temporal Gyrus; NAcc, Nucleus Accumbens.

\section{OXTR AND BRAIN MECHANISMS UNDERLYING COOPERATION}

In this section, we will consider the association between the OXTR gene and specific social-cognitive constructs and brain networks that subserve cooperation. There is some evidence that the OXTR gene is associated with emotion recognition. Lucht et al. (2012) and Rodrigues et al. (2009) reported that performance on the "Reading the Mind in the Eyes Test" varied according to OXTR polymorphisms. Additional, indirect support for the association between OT genes and emotion recognition comes from evidence that OT administration improves people's ability to recognize emotions (Domes et al., 2007; Bartz et al., 2010; Guastella et al., 2010).
In terms of the brain, magnetic resonance imaging studies (MRI) studies show that the OXTR gene is associated with the structure and function of a subset of brain regions involved in emotion recognition (Figure 1A). O'Connell et al. (2012) demonstrated that OXTR polymorphisms are associated with VC (cuneus and inferior occipital gyrus) reactivity to fearful faces. In terms of the amygdala, both Furman et al. (2011) and Inoue et al. (2010) showed an association between the OXTR gene and amygdala volume and Tost et al. (2010) showed that the OXTR gene is associated with amygdala activity during an emotional face-matching task. For the FG, O'Connell et al. (2012) directly tested for activation differences according to OXTR variants within this region, but failed to identify any significant differences. 
A recent study investigated the association between methylation ${ }^{1}$ of the OXTR gene and brain function during biological motion processing (Jack et al., 2012). The results indicated that increased methylation (typically associated with decreased expression) of OXTR is associated with greater activation within the superior temporal gyrus (STG). Although biological motion is more often linked with the function of the STS, this study provides preliminary evidence that the OXTR gene is associated with neural reactivity during the recognition of social information. Lastly, it is currently unknown if the OXTR gene is associated with the structure or function of the dorsolateral or VMPFC in humans.

There is evidence that the OXTR gene may be linked to individual differences in empathy and theory of mind. Behavioral studies show that OXTR is associated with self reported empathy (Rodrigues et al., 2009). Furthermore, Wu et al. (2012) demonstrated that distinct polymorphisms of the OXTR gene are associated with emotional and cognitive (i.e., theory of mind) empathy. In terms of the brain, there is evidence that the OXTR gene is associated with the structure and function of brain regions involved in emotional empathy (Figure 1B). Specifically, Furman et al. (2011) and Tost et al. (2010, 2011) demonstrated volumetric differences of the dorsal ACC according to OXTR polymorphisms. In terms of function, Tost et al. (2011) showed that the OXTR gene is associated with dorsal ACC activity during emotional face processing. However, it is currently unknown if OXTR is associated with the structure or function of key brain regions involved in cognitive empathy/theory or mind, such as the temporal parietal junction.

The OXTR gene may be linked to the ability to socially communicate. Behavioral research shows that OXTR is associated with the ability to comprehend information during vocal communication (Tops et al., 2011) and with the severity of communication deficits in autism (Jacob et al., 2007; Lerer et al., 2007; Campbell et al., 2011). There is limited evidence that OXTR is linked to brain mechanisms underlying social communication (Figure 1C). However, indirect support comes from research on the effect of OT administration on brain reactivity to vocal social signals (Riem et al., 2011, 2012). Riem et al. (2011) showed that parents that receive OT administration exhibit greater left inferior frontal gyrus reactivity to sounds of their child crying as compared to parents receiving placebo. In addition, OXTR methylation status is associated with left STG activation (Jack et al., 2012). However, the association between OXTR methylation and STG activity was found in response to a biological motion processing task. Therefore, it is currently unknown if the OXTR gene is associated with the functional anatomy of the STG when socially communicating. In addition, it is currently unknown how OXTR polymorphisms may affect the structure or function of other regions involved in social communication that include the inferior frontal gyrus and premotor area.

The OXTR gene may be associated with individual differences in social reward processing. Behavioral studies indicate that the OXTR gene is associated with trait reward sensitivity (Tost et al., 2010) and social motivation deficits in autism (Campbell et al., 2011). In terms of the brain, there is some evidence that the OXTR

\footnotetext{
${ }^{1}$ Methylation is an epigenetic process that affects the expression of genes.
}

gene is associated with the structure and function of a subset of regions involved in reward processing (Figure 1D). Polymorphisms of OXTR are associated with ACC reactivity during emotion processing (Tost et al., 2011). In addition OXTR is associated with volumetric differences of the ACC (Tost et al., 2010; Furman et al., 2011). Indirect support of the association between OXTR and the neural basis of reward processing comes from research on the link between OXTR and dopamine transmission. Love et al. (2012), used positron emission tomography and showed that OXTR is associated with dopamine levels within the striatum in females. Lastly, research on animals demonstrates that the nucleus accumbens is densely populated with OT receptors (Ross et al., 2009). It is currently unknown however, how the OXTR gene affects the functional anatomy of the Nacc and VMPFC in humans.

A review of the research to date demonstrates that the OXTR gene may influence the functional anatomy of a subset of the brain regions implicated in cooperation. For emotion recognition, the OXTR gene is associated with the structure (Inoue et al., 2010; Furman et al., 2011) and function (Tost et al., 2010) of the amygdala and the function of the VC (O'Connell et al., 2012). This indicates that the OXTR gene may be associated with attention to emotionally salient stimuli, but not necessarily with face processing (fusiform gryus) or higher order categorization and evaluation of emotional stimuli (VMPFC and DLPFC). For empathy and theory of mind, the OXTR gene is associated with the structure (Tost et al., 2010, 2011; Furman et al., 2011) and function (Tost et al., 2011) of the ACC, though there is currently no evidence that OXTR is associated with the structure or function of the TPJ. These findings suggest that the OXTR gene may influence brain regions involved in emotional but not cognitive empathy. In terms of social communication, there is one study showing an association between OXTR methylation and the function of the STG (Jack et al., 2012). Therefore, it is currently not known how OXTR polymorphisms are linked to the functional anatomy within brain important for social communication. Lastly, for social reward processing, there is evidence that OXTR is associated with the structure (Tost et al., 2010, 2011; Furman et al., 2011) and function (Tost et al., 2011) of the ACC. In spite of many animal studies demonstrating that the NAcc is densely populated with OT receptors (Hammock and Young, 2006), it is currently unknown how the OXTR gene may affect the functional anatomy of the NAcc in humans.

\section{POTENTIAL FUTURE RESEARCH DIRECTIONS AND CONCLUSION}

There is currently a lack of evidence that the OXTR gene is associated with brain function during tasks that explicitly involve cooperation. One potential strategy to elucidate the association between OXTR and the brain basis of cooperation is to utilize a version of the prisoner's dilemma task that can be used within a brain imaging environment (Rilling et al., 2012) and compare patterns of brain reactivity according to OXTR polymorphisms.

In addition, a potential strategy to explore how the OXTR gene may be associated with face processing is to use tasks and analysis procedures specifically designed to quantify the spatial extent of the fusiform face area (Weiner and Grill-Spector, 2012). 
Support for the hypothesis that the OXTR gene is associated with emotional but not cognitive empathy may be obtained by using fMRI tasks designed to explicitly compare types of empathic processing (Sebastian et al., 2012). For social communication, MRI studies show that emotional prosody relies on a specific network of brain regions (Ethofer et al., 2006; Wiethoff et al., 2008). Emotional prosody tasks may be a promising tool to explore the association between OXTR and brain networks subserving social communication. Lastly, an effective way to investigate the association between OXTR and social reward processing may be to utilize tasks explicitly designed to assess social versus nonsocial (monetary) reward processing (Gossen et al., 2013). Based on findings that social relevance boosts the influence of OT on cooperative behavior (Declerck et al., 2010, 2013), the OXTR gene may have a greater impact on brain function during social reward processing as compared to monetary reward processing.

In this review, we have focused on a network of key brain regions involved in cooperation. In conclusion, there is limited evidence that the OXTR gene is directly linked to the functional anatomy of the brain network implicated in cooperation. The use of endophenotypes is a promising strategy that may help to elucidate this complex gene, brain and social-cognitive association.

\section{REFERENCES}

Aggleton, J. P. (2000). The Amygdala: A Functional Analysis. New York: Oxford University Press, (Chapter Chapter).

Apicella, C. L., Cesarini, D., Johannesson, M., Dawes, C. T., Lichtenstein, P., Wallace, B., et al. (2010). No association between oxytocin receptor (OXTR) gene polymorphisms and experimentally elicited social preferences. PLoS One 5:e11153. doi: 10.1371/journal.pone.0011153

Bartz, J. A., Zaki, J., Bolger, N., Hollander, E., Ludwig, N. N., Kolevzon, A., et al. (2010). Oxytocin selectively improves empathic accuracy. Psychol. Sci. 21, 14261428. doi: $10.1177 / 0956797610383439$

Brosnan, S. F., Salwiczek, L., and Bshary, R. (2010). The interplay of cognition and cooperation. Philos. Trans. R. Soc. Lond. B Biol. Sci. 365, 2699-2710. doi: 10. 1098/rstb.2010.0154

Campbell, D. B., Datta, D., Jones, S. T., Batey Lee, E., Sutcliffe, J. S., Hammock, E. A., et al. (2011). Association of oxytocin receptor (OXTR) gene variants with multiple phenotype domains of autism spectrum disorder. J. Neurodev. Disord. 3, 101-112. doi: 10.1007/s11689-010-9071-2

Cesarini, D., Dawes, C. T., Fowler, J. H., Johannesson, M., Lichtenstein, P., and Wallace, B. (2008). Heritability of cooperative behavior in the trust game. Proc. Natl. Acad. Sci. U S A 105, 3721-3726. doi: 10.1073/pnas.0710069105

Cloninger, C. R., Svrakic, D. M., and Przybeck, T. R. (1993). A psychobiological model of temperament and character. Arch. Gen. Psychiatry 50, 975-990. doi: 10. 1001/archpsyc. 1993.01820240059008

Decety, J., and Lamm, C. (2007). The role of the right temporoparietal junction in social interaction: how low-level computational processes contribute to metacognition. Neuroscientist 13, 580-593. doi: 10.1177/1073858407304654

Declerck, C., Boone, C., and Kiyonari, T. (2010). Oxytocin and cooperation under conditions of uncertainty: the modulating role of incentives and social information. Horm. Behav. 57, 368-374. doi: 10.1016/j.yhbeh.2010.01.006

Declerck, C., Boone, C., and Kiyonari, T. (2013). The effect of oxytocin on cooperation in a prisoner's dilemma depends on the social context and a person's social value orientation. Soc. Cogn. Affect. Neurosci. doi: 10.1093/scan/nst040. [Epub ahead of print].

Domes, G., Heinrichs, M., Michel, A., Berger, C., and Herpertz, S. C. (2007). Oxytocin improves "mind-reading" in humans. Biol. Psychiatry 61, 731-733. doi: 10.1016/j.biopsych.2006.07.015

Ebstein, R. P., Knafo, A., Mankuta, D., Chew, S. H., and Lai, P. S. (2012). The contributions of oxytocin and vasopressin pathway genes to human behavior. Horm. Behav. 61, 359-379. doi: 10.1016/j.yhbeh.2011.12.014

Elfenbein, H. A., Foo, M. D., White, J., Tan, H. H., and Aik, V. C. (2007). Reading your counterpart: the benefit of emotion recognition accuracy for effectiveness in negotiation. J. Nonverbal. Behav. 31, 205-223. doi: 10.1007/s10919-0070033-7

Ethofer, T., Anders, S., Erb, M., Herbert, C., Wiethoff, S., Kissler, J., et al. (2006). Cerebral pathways in processing of affective prosody: a dynamic causal modeling study. Neuroimage 30, 580-587. doi: 10.1016/j.neuroimage.2005.09. 059

Fan, Y., Duncan, N. W., de Greck, M., and Northoff, G. (2010). Is there a core neural network in empathy? An fMRI based quantitative meta-analysis. Neurosci. Biobehav. Rev. 35, 903-911. doi: 10.1016/j.neubiorev.2010.10.009

Furman, D. J., Chen, M. C., and Gotlib, I. H. (2011). Variant in oxytocin receptor gene is associated with amygdala volume. Psychoneuroendocrinology 36, 891897. doi: 10.1016/j.psyneuen.2010.12.004

Gimpl, G., and Fahrenholz, F. (2001). The oxytocin receptor system: structure, function, and regulation. Physiol. Rev. 81, 629-683.

Gossen, A., Groppe, S. E., Winkler, L., Kohls, G., Herrington, J., Schultz, R. T., et al. (2013). Neural evidence for an association between social proficiency and sensitivity to social reward. Soc. Cogn. Affect. Neurosci. doi: 10.1093/scan/nst033. [Epub ahead of print].

Gottesman, I. I., and Gould, T. D. (2003). The endophenotype concept in psychiatry: etymology and strategic intentions. Am. J. Psychiatry 160, 636-645. doi: 10. 1176/appi.ajp.160.4.636

Guastella, A. J., Einfeld, S. L., Gray, K. M., Rinehart, N. J., Tonge, B. J., Lambert, T. J., et al. (2010). Intranasal oxytocin improves emotion recognition for youth with autism spectrum disorders. Biol. Psychiatry 67, 692-694. doi: 10.1016/j. biopsych.2009.09.020

Haber, S. N., and Knutson, B. (2009). The reward circuit: linking primate anatomy and human imaging. Neuropsychopharmacology 35, 4-26. doi: 10.1038/npp. 2009.129

Hamer, D. (2002). Rethinking behavior genetics. Science 298, 71-72. doi: 10. 1126/science.1077582

Hammock, E. A., and Young, L. J. (2006). Oxytocin, vasopressin and pair bonding: implications for autism. Philos. Trans. R. Soc. Lond. B Biol. Sci. 361, 2187-2198. doi: 10.1098/rstb.2006.1939

Hein, G., and Knight, R. T. (2008). Superior temporal sulcus-It's my area: or is it? J. Cogn. Neurosci. 20, 2125-2136. doi: 10.1162/jocn.2008.20148

Hickok, G., and Poeppel, D. (2007). The cortical organization of speech processing. Nat. Rev. Neurosci. 8, 393-402. doi: 10.1038/nrn2113

Inoue, H., Yamasue, H., Tochigi, M., Abe, O., Liu, X., Kawamura, Y., et al. (2010). Association between the oxytocin receptor gene and amygdalar volume in healthy adults. Biol. Psychiatry 68, 1066-1072. doi: 10.1016/j.biopsych.2010.07. 019

Israel, S., Lerer, E., Shalev, I., Uzefovsky, F., Riebold, M., Laiba, E., et al. (2009). The oxytocin receptor (OXTR) contributes to prosocial fund allocations in the dictator game and the social value orientations task. PLoS One 4: e5535. doi: 10. 1371/journal.pone.0005535

Jack, A., Connelly, J. J., and Morris, J. P. (2012). DNA methylation of the oxytocin receptor gene predicts neural response to ambiguous social stimuli. Front. Hum. Neurosci. 6:280. doi: 10.3389/fnhum.2012.00280

Jacob, S., Brune, C. W., Carter, C. S., Leventhal, B. L., Lord, C., and Cook, Jr. E. H. (2007). Association of the oxytocin receptor gene (OXTR) in caucasian children and adolescents with autism. Neurosci. Lett. 417, 6-9. doi: 10.1016/j.neulet.2007. 02.001

Kanwisher, N., McDermott, J., and Chun, M. M. (1997). The fusiform face area: a module in human extrastriate cortex specialized for face perception. J. Neurosci. $17,4302-4311$.

Kimura, T., Tanizawa, O., Mori, K., Brownstein, M. J., and Okayama, H. (1992). Structure and expression of a human oxytocin receptor. Nature 356, 526-529. doi: $10.1038 / 357176 \mathrm{~b} 0$

Komorita, S. S., and Parks, C. D. (1999). "Reciprocity and cooperation in social dilemmas: review and future directions," in Games and Human Behavior: Essays in Honor of Amnon Rapoport, eds D. V. Budescu, I. Erev and R. Zwick (Mahwah, NJ: Lawrence Erlbaum Associates Publishers), 315-330.

Kosfeld, M., Heinrichs, M., Zak, P. J., Fischbacher, U., and Fehr, E. (2005). Oxytocin increases trust in humans. Nature 435, 673-676. doi: 10.1038/nature03701

Krumhuber, E., Manstead, A. S., Cosker, D., Marshall, D., Rosin, P. L., and Kappas, A. (2007). Facial dynamics as indicators of trustworthiness and cooperative behavior. Emotion 7, 730-735. doi: 10.1037/1528-3542.7.4.730

Lerer, E., Levi, S., Salomon, S., Darvasi, A., Yirmiya, N., and Ebstein, R. (2007). Association between the oxytocin receptor (OXTR) gene and autism: relation- 
ship to vineland adaptive behavior scales and cognition. Mol. psychiatry 13, 980988. doi: 10.1038/sj.mp. 4002087

Love, T. M., Enoch, M.-A., Hodgkinson, C. A., Peciña, M., Mickey, B., Koeppe, R. A., et al. (2012). Oxytocin gene polymorphisms influence human dopaminergic function in a sex-dependent manner. Biol. Psychiatry 72, 198-206. doi: 10. 1016/j.biopsych.2012.01.033

Lucht, M. J., Barnow, S., Sonnenfeld, C., Ulrich, I., Grabe, H. J., Schroeder, W., et al. (2012). Associations between the oxytocin receptor gene (OXTR) and "mindreading" in humans-an exploratory study. Nord. J. Psychiatry 67, 15-21. doi: 10. 3109/08039488.2012.700731

Miller, J. H., Butts, C. T., and Rode, D. (2002). Communication and cooperation. J. Econ. Behav. Organ. 47, 179-195. doi: 10.1016/S0167-2681(01)00159-7

Mitchell, D. G., and Greening, S. G. (2012). Conscious perception of emotional stimuli: brain mechanisms. Neuroscientist 18, 386-398. doi: 10. $1177 / 1073858411416515$

Morris, J. S., Friston, K. J., Buchel, C., Frith, C. D., Young, A. W., Calder, A. J., et al. (1998). A neuromodulatory role for the human amygdala in processing emotional facial expressions. Brain, 121(Pt 1), 47-57. doi: 10.1093/brain/121. 1.47

O'Connell, G., Whalley, H. C., Mukherjee, P., Stanfield, A. C., Montag, C., Hall, J., et al. (2012). Association of genetic variation in the promoter region of OXTR with differences in social affective neural processing. J. Behav. Brain Sci. 2, 6066. doi: 10.4236/jbbs.2012.21007

Paal, T., and Bereczkei, T. (2007). Adult theory of mind, cooperation, machiavellianism: the effect of mindreading on social relations. Pers. Individ. Dif. 43, 541551. doi: 10.1016/j.paid.2006.12.021

Price, C. J. (2012). A review and synthesis of the first 20 years of PET and fMRI studies of heard speech, spoken language and reading. Neuroimage 62, 816-847. doi: 10.1016/j.neuroimage.2012.04.062

Riem, M. M., Bakermans-Kranenburg, M. J., Pieper, S., Tops, M., Boksem, M. A., Vermeiren, R. R., et al. (2011). Oxytocin modulates amygdala, insula, and inferior frontal gyrus responses to infant crying: a randomized controlled trial. Biol. Psychiatry 70, 291-297. doi: 10.1016/j.biopsych.2011.02.006

Riem, M. M., van, I. M. H., Tops, M., Boksem, M. A., Rombouts, S. A., and Bakermans-Kranenburg, M. J. (2012). No laughing matter: intranasal oxytocin administration changes functional brain connectivity during exposure to infant laughter. Neuropsychopharmacology 37, 1257-1266. doi: 10.1038/npp. 2011.313

Rilling, J. K., DeMarco, A. C., Hackett, P. D., Thompson, R., Ditzen, B., Patel, R., et al. (2012). Effects of intranasal oxytocin and vasopressin on cooperative behavior and associated brain activity in men. Psychoneuroendocrinology 37, 447-461. doi: 10.1016/j.psyneuen.2011.07.013

Rodrigues, S. M., Saslow, L. R., Garcia, N., John, O. P., and Keltner, D. (2009). Oxytocin receptor genetic variation relates to empathy and stress reactivity in humans. Proc. Natl. Acad. Sci. U S A 106, 21437-21441. doi: 10.1073/pnas. 0909579106

Ross, H. E., Freeman, S. M., Spiegel, L. L., Ren, X., Terwilliger, E. F., and Young, L. J. (2009). Variation in oxytocin receptor density in the nucleus accumbens has differential effects on affiliative behaviors in monogamous and polygamous voles. J. Neurosci. 29, 1312-1318. doi: 10.1523/jneurosci.5039-08. 2009

Roy, M., Shohamy, D., and Wager, T. D. (2012). Ventromedial prefrontalsubcortical systems and the generation of affective meaning. Trends Cogn. Sci. 16, 147-156. doi: 10.1016/j.tics.2012.01.005

Rudrauf, D., David, O., Lachaux, J.-P., Kovach, C. K., Martinerie, J., Renault, B., et al. (2008). Rapid interactions between the ventral visual stream and emotionrelated structures rely on a two-pathway architecture. J. Neurosci. 28, 2793-2803. doi: 10.1523/jneurosci.3476-07.2008

Rushworth, M. F., Noonan, M. P., Boorman, E. D., Walton, M. E., and Behrens, T. E. (2011). Frontal cortex and reward-guided learning and decision-making. Neuron 70, 1054-1069. doi: 10.1016/j.neuron.2011.05.014

Sally, D., and Hill, E. (2006). The development of interpersonal strategy: autism, theory-of-mind, cooperation and fairness. J. Econ. Psychol. 27, 73-97. doi: 10. 1016/j.joep.2005.06.015
Sebastian, C. L., Fontaine, N. M., Bird, G., Blakemore, S. J., Brito, S. A., McCrory, E. J., et al. (2012). Neural processing associated with cognitive and affective theory of mind in adolescents and adults. Soc. Cogn. Affect. Neurosci. 7, 53-63. doi: $10.1093 / \mathrm{scan} / \mathrm{nsr} 023$

Tabak, B. A., McCullough, M. E., Carver, C. S., Pedersen, E. J., and Cuccaro, M. L. (2013). Variation in oxytocin receptor gene (OXTR) polymorphisms is associated with emotional and behavioral reactions to betrayal. Soc. Cogn. Affect. Neurosci. doi: 10.1093/scan/nst042. [Epub ahead of print].

Thompson, J., and Parasuraman, R. (2012). Attention, biological motion, and action recognition. Neuroimage 59, 4-13. doi: 10.1016/j.neuroimage.2011.05. 044

Tops, M., Van IJzendoorn, M. H., Riem, M. M., Boksem, M. A., and BakermansKranenburg, M. J. (2011). Oxytocin receptor gene associated with the efficiency of social auditory processing. Front. Psychiatry 2:60. doi: 10.3389/fpsyt.2011. 00060

Tost, H., Kolachana, B., Hakimi, S., Lemaitre, H., Verchinski, B. A., Mattay, V. S., et al. (2010). A common allele in the oxytocin receptor gene (OXTR) impacts prosocial temperament and human hypothalamic-limbic structure and function. Proc. Natl. Acad. Sci. U S A 107, 13936-13941. doi: 10.1073/pnas. 1003296107

Tost, H., Kolachana, B., Verchinski, B. A., Bilek, E., Goldman, A. L., Mattay, V. S., et al. (2011). Neurogenetic effects of OXTR rs2254298 in the extended limbic system of healthy caucasian adults. Biol. Psychiatry 70, e37-e39. doi: 10.1016/j. biopsych.2011.06.034

Volk, S., Thöni, C., and Ruigrok, W. (2011). Personality, personal values and cooperation preferences in public goods games: a longitudinal study. Pers. Individ. Dif. 50, 810-815. doi: 10.1016/j.paid.2011.01.001

Weiner, K. S., and Grill-Spector, K. (2012). The improbable simplicity of the fusiform face area. Trends Cogn. Sci. 16, 251-254. doi: 10.1016/j.tics.2012.03. 003

Wiethoff, S., Wildgruber, D., Kreifelts, B., Becker, H., Herbert, C., Grodd, W., et al. (2008). Cerebral processing of emotional prosody-influence of acoustic parameters and arousal. Neuroimage 39, 885-893. doi: 10.1016/j.neuroimage. 2007.09.028

Wischniewski, J., Windmann, S., Juckel, G., and Brune, M. (2009). Rules of social exchange: game theory, individual differences and psychopathology. Neurosci. Biobehav. Rev. 33, 305-313. doi: 10.1016/j.neubiorev.2008. 09.008

Witt, L., Burke, L. A., Barrick, M. A., and Mount, M. K. (2002). The interactive effects of conscientiousness and agreeableness on job performance. J. Appl. Psychol. 87, 164-169. doi: 10.1037//0021-9010.87.1.164

$\mathrm{Wu}, \mathrm{N} ., \mathrm{Li}, \mathrm{Z}$., and Su, Y. (2012). The association between oxytocin receptor gene polymorphism (OXTR) and trait empathy. J. Affect. Disord. 138, 468-472. doi: 10.1016/j.jad.2012.01.009

Yamasue, H. (2013). Function and structure in social brain regions can link oxytocin-receptor genes with autistic social behavior. Brain Dev. 35, 111-118. doi: 10.1016/j.braindev.2012.08.010

Conflict of Interest Statement: The authors declare that the research was conducted in the absence of any commercial or financial relationships that could be construed as a potential conflict of interest.

Received: 01 March 2013; accepted: 04 November 2013; published online: 28 November 2013.

Citation: Haas BW, Anderson IW and Smith JM (2013) Navigating the complex path between the oxytocin receptor gene (OXTR) and cooperation: an endophenotype approach. Front. Hum. Neurosci. 7:801. doi: 10.3389/fnhum.2013.00801

This article was submitted to the journal Frontiers in Human Neuroscience.

Copyright $\odot 2013$ Haas, Anderson and Smith. This is an open-access article distributed under the terms of the Creative Commons Attribution License (CC BY). The use, distribution or reproduction in other forums is permitted, provided the original author $(s)$ or licensor are credited and that the original publication in this journal is cited, in accordance with accepted academic practice. No use, distribution or reproduction is permitted which does not comply with these terms. 